\title{
SISTEM INFORMASI PERINGATAN DINI BENCANA PADA KOTA PAGAR ALAM BERBASIS MOBILE
}

\author{
Yogi Isro' Mukti ${ }^{1}$, Desi Puspita ${ }^{2}$ \\ ${ }^{1}$ Program Studi Teknik Informatika, Sekolah Tinggi Teknologi Pagar Alam, Pagar Alam \\ e-mail: *1yogie.isro.mukti@ sttpagaralam.ac.id, ${ }^{2}$ desiofira@sttpagaralam.ac.id,
}

\begin{abstract}
Abstrak
Penelitian ini bertujuan untuk membuat sebuah sistem informasi peringatan dini bencana pada Kota Pagar Alam berbasis mobile. Pagar Alam sendiri merupakan sebuah kota yang terletak di Provinsi Sumatera Selatan, dengan kondisi geografis di area pegunungan yang memiliki banya perkebunan dan kawasan hutan. Yang merupakan kawasan lawan longsor karena memiliki kontur tanah yang lembut. Terutama pada musim penghujan yang memiliki intensitas curah hujan yang tinggi. Selain itu perkembangan pemukiman warga yang semakin padat juga menjadi penyebab Pagar Alam menjadi daerah yang rawan bencana terutama longsor. Selain itu juga merupakan daerah kawasan hutang yang merupakan aspek penting dalam penyediaan air bersih, jika dimusim kemarau bisa menyebabkan suhu panas tinggi dan bisa menyebabkan kebakaran. Oleh karena itu peneliti membuat sebuah sistem informasi peringatan dini bencana Pada Kota Pagar Alam berbasis mobile dengan Metode pengembangan sistem yangdigunakan adalah Rapid Aplication Development (RAD). Penelitian ini menghasilkan sistem informasi peringatan dini ini, dapat memberikan informasi kepada masyarakat Kota Pagar Alam untuk mengantisipasi akan terjadinya longsor, serta memberikan edukasi terkait pemukiman warga yang menjadi area rawan longsor, dan juga memberikan informasi terkait peningkatan suhu yang bisa menyebabkan kebakaran lahan dan hutan, yang bisa diakses dengan perangkat mobile seperti smartphone, tablet, tab, baik dengan sistem operasi android, mapun IOS, sehingga Tingkat Kesiapan Teknologi (TKT) yang dikembangkan siap untuk diintegrasikan.
\end{abstract}

Kata kunci - sistem informasi, peringatan dini bencana, longsor, kebakaran, RAD

\begin{abstract}
This study aims to create an information system for disaster early warning in Kota Pagar Alam based on mobile. Pagar Alam itself is a city located in South Sumatra Province, with geographical conditions in mountainous areas that have many plantations and forest areas. Which is an area against landslides because it has soft soil contours. Especially in the rainy season which has a high rainfall intensity. In addition, the development of increasingly dense community settlements also causes Pagar Alam to become a disaster-prone area, especially landslides. It is also an area of debt area which is an important aspect in the provision of clean water, if the dry season can cause high heat and can cause fires. Therefore, researchers created a disaster early warning information system in the city of Pagar Alam based on mobile with the system development method used is Rapid Application Development (RAD). This research produces an early warning information system, can provide information to the people of the City of Pagar Alam to anticipate the occurrence of landslides, as well as provide education related to residential areas that are prone to landslides, and also provide information related to rising temperatures that can cause land and forest fires, which can be accessed by mobile devices such as smartphones, tablets, tabs, both with the Android operating system, or IOS, so that the Technology Readiness Level (TKT) developed is ready to be integrated.
\end{abstract}

Keywords - information systems, disaster early warning, landslides, fires, RAD 


\section{PENDAHULUAN}

Bencana merupakan persoalan yang sering dihadapi di Indonesia setiap tahunnya, Pada tahun 2018 BNPB mencatat untuk provinsi yang banyak terjadi bencana adalah Jawa Tengah 315 kejadian, dan untuk daerah sumatera yang banyak terjadi bencana adalah wilayah Sumatera Selatan sebanyak 51 kejadian. Bencana yang sering terjadi di daerah dan hampir tiap tahun seperti banjir, tanah longsor dan gempa bumi, kebakaran. Bencana yang dihadapi tiap tahunnya adalah bencana kebakaran hutan. berdasarkan data rekapitulasi dari tahun 2014-2019 sipongi.menlhk.go.id, [1] Direktorat PKHL Kementerian Lingkungan Hidup dan Kehutanan Republik Indonesia, menunjukan tingkat kebakaran lahan pada tahun 2014 sebanyak 44.411,36 ha, tahun 2015 sebanyak 2.611.411,44 ha, tahun 2016 sebanyak 438.363,19 ha, tahun 2017 sebanyak 165.483,92 ha, tahun 2018 sebanyak 510.564,21 ha, dan pada tahun 2019 sebanyak 135.749,00 ha. Yang secara umum ada penurunan sejak rekor terburuk pada tahun 2015. Namun demikian dibeberapa provinsi masih menunjukan peningkatan kebakaran hutan masih tinggi salah satunya di wilayah sumatera yakni sumatera selatan yang mengalami peningkatan kebakaran hutan dan lahan tiap tahunya dan pada tahun 2018 mencapai 13.019,68 ha.

Selain kebakaran lahan persoalan yang dihadapi ketika memasuki musim penghujan adalah banjir dan tanah longsor, seperti yang terjadi pada ruas jalan nasional yang menghubungkan antara Kota Pagar Alam dan Lahat mengalami putus total akibat longsor. Longsor terjadi pada dini hari akibat diguyur hujan terus menerus menyebabkan kontur tanah menjadi rentan dan menyebabkan longsor.[2]

Persoalan kebakaran hutan dan lahan serta longosr merupakan bencana daerah yang menjadi tantangan sendiri pada setiap daerah di Sumatera Selatan, seperti di Kota Pagar Alam yang meliputi 5 (Lima) Kecamatan, 35 Kelurahan. Luas Wilayah 633,66 Km 2 atau $63.366 \mathrm{Ha}$, dengan ketinggian bervariasi dari $100 \mathrm{~m}$ sampai > $1000 \mathrm{~m}$ dari permukaan laut. Jenis tanah terdiri dari andosol dan latosol coklat dengan permukaan bergelombang sampai berbukit. Kota Pagar Alam secara geografis terletak antara 040 Lintang Selatan (LS), dan 103,150 Bujur Timur (BT). Daerah yang berbukit hingga bergunung dengan ketinggian $1.250 \mathrm{~m}$ - $3.195 \mathrm{mdpl}$. Daerah landai dengan ketinggian antara $441-1.000$ $\mathrm{m}$ di atas permukaan laut. Rata rata curah hujan $1.462 \mathrm{~mm}-5.199 \mathrm{~mm}$ per tahun dengan jumlah bulan basah lebih enam bulan per tahun. Suhu berkisar antara $200-280 \mathrm{C}$ dan intensitas cahaya matahari antara 6-10 jam perhari. Dengan kondisi geografis yang berada di area penggunungan, dan merupakan kawasan hutan dan perkebunan.

Pagar Alam merupakan rawan bencana terutama tanah longsor mengingat kondisi tanah yang ada berada di area perbukitan dan gunung yang rapuh, terutama jika terjadi musim penghujan. Untuk itu perlu adanya pemetaan pada wilayah yang rawan atau terindikasi bisa terjadi bencana, baik banjir maupun tanah longsor, dan menginformasikan kepada masyarkat terhadap wilayah tersebut, agar menjadi peringatan untuk lebih berhati-hati. Untuk itu perlu adanya penanganan yang serius dari berbagai pihak untuk menghindari dampak dari bencana, hal ini susuai dengan UU Nomor 24 Tahun 2007 tentang penanggulangan bencana dengan tujuannya adalah memberikan perlindungan kepada masyarakat dari ancaman bencana. Salah satu cara yang bisa dilakukan dalam penanggulangan bencana adalah dengan memberikan sebuah sistem peringatan dan pemetaan terhadap daerah yang dianggap rawan terjadi bencana secara real time yang bersifat mobile. Mengingat penggunaan 
smartphone pada masyarakat tiap tahunnya semakin meningkat. Beradasarkan data Lebaga riset digital marketing emarketer memperkirakan pada 2018 jumlah pengguna aktif $>100$ juta orang.[3]

Untuk mengatisipasi persoalan kebencanaan tersebut maka diperlukan sebuah sistem peringatan dini bencana daerah yang mamapu memberikan informasi terkait kebencanaan yang ada di Kota Pagar Alam, yang bersifat mobile, sehingga bisa diakses dari mana saja dan kapan saja.

\section{TINJAUAN PUSTAKA}

\subsection{Sistem Informasi}

Menurut Bambang Hartono dalam bukunya [4] disimpulkan sistem merupakan bagian dari sebuah elemen atau lebih yang mempunyai keterkaitan yang tersusun atas dasar fungsinya, dalam satu kesatuan yang terhubung. Kesimpulan ini berdasar pada dua definisi sistem yang dikemukakan oleh Schrode dan Voich, serta pendapat Elias M.Awad.

Definisi-definisi tentang sistem tergambar yang memiliki makna primer yaitu objek atau kumpulan dari objek baik sebagian atau keseluruhan komponen objek, seta suatu metode yang terorganisasi sesuai dengan fungsinya.[4]

Menurut (Ward \& Peppard), dapat disimpulkan bahawa information system adalah cara dalam menerapkan dan mengimplementasikan teknologi serta menyebarkannnya.[5]

Sedangkan menurut Ferdinand Magalin di dalam buku Hoga Saragih dan Harisno(Saragih \& Harisno, 2014), Sistem Informasi adalah suatu sistem yang ada dalam perusahaan, yang memiliki peran strategis dalam pengelolaan harian, dan juga fungsi manajerial dalam memberikan informasi strategis yang diperlukan pada pihak luar.[6]

Menurut Hoga Saragih dan Harisno(Saragih \& Harisno, 2014) mengemukakan bahwa sistem informasi yakni sebuah mekanisme yang memberikan informasi bagi perusahaan dalam pengelolaan, baik membuat, merubah menjadikan sebuah sistem informasi yang bermanfaat dan mengkomunikasikannya.

Pemanfaatan teknologi informasi banyak digunakan baik dalam mendukung perekonomian, pendidikan, pemerintahan, yang memiliki nilai ekonomis dalam mendukung bisnis perusahaan

\subsection{Peringatan Dini}

Peringatan Bencana Menurut Berdasarkan Undang-undang Nomor 24 Tahun 2007 Pasal 1, merupakan suatu cara dalam memberikan informasi berupa peringatan dini kepada elemen masyarakat terkait dengan kebencanaan. sedangkan mitigasi adalah suatu upaya dalam menanggulangi resiko kebencanaan yang ada, seperti pembangunan infrastruktur maupun sosialisasi terkait penyadaran, dan peningkatan masyarakat dalam menanggulangi kebencanaan.

Defenisi pada pasal tersebut merupakan dampak dari kebencanaan baik yang disebabkan oleh faktor alam maupun oleh ulah tangan manusia, dan definisi pada pasal tersebut juga merupakan kebencanaan baik dari sektor alam maupun sosial.[7]

\subsection{Mobile Aplikasi}

Mobile sendiri diartikan sebuah perangkat bergerak yang juga dikenal sebagai perangkat genggam,telepon genggam, yang merupakan sebuah peralatan komputer yang sukuran kantong, yang memiliki layer sentuh atau papan ketik mini.[8]

Pertama, Menurut Techopedia dalam buku Hendra Santoso, [9] mengatakan, aplikasi native adalah aplikasi smartphone yang dibuat dalam Bahasa pemrograman tertentu, seperti Swift dan Objective C 
untuk Ios, Java untuk Android atau Net untuk platform Windows.

Aplikasi native sendiri memberikan kinerja cepat dan tingkat keandalan yang tinggi, selain itu juga memiliki akses ke berbagai perangkat smartphone, seperti kamera, address book dan lainnya. Selain itu pengguna dapat menggunakan beberapa aplikasi tanpa koneksi internet.

Namun demikian, jenis aplikasi ini mahal untuk dikembangkan, karena terikat pada satu jenis sistem operasi, sehingga perusahaan umumnya membuat versi duplikat dari aplikasi native yang berfungsi pada platform lain. Sebagian besar aplikasi video game untuk perangkat mobile adalah aplikasi mobile native.[9]

Kedua Hybrid Mobile App adalah jenis aplikasi mobile yang memiliki kemampuan cross-platform, dapat berjalan di berbagai jenis perangkat, baik Ios, Android, Windows, atau sistem operasi lainnya. Aplikasi Mobile Hybrid di download dari App Store, sama seperti Aplikasi Mobile Native. Pemrograman Hybride menggunakan teknologi web, seperti HTML, CSS, Javascript yang berjalan di webview (engine browser yang berjalan diaplikasi mobile)[9]

Ketiga, Progressive Web App, merupakan aplikasi web dengan karakteristik seperti aplikasi mobile native, yang dibangun menggunakan teknologi web modern, namun berlaku seperti sebuah mobile app.[9]

Pada tahun 2015, Google engineer Alex Russell dan Frances Berriman memberikan istilah Progressive Web Apps pada konsep web apps yang memberikan user experience dalam keandalan (reliability), kecepatan (speed), dan keterlibatan pengguna (user engagement).

\subsection{Penelitian Terdahulu}

Penelitian yang dilakukan sejalan dengan penelitian sebelumnya, dengan mengkombinasikan antaran teknologi sensor dengan kontroler dan juga memadukan dengan programming berbasis mobil, diantaranya penelitian yang menjadi rujukan yakni :

Penelitian yang dilakukan oleh Dedi Satria, dkk. Menghasilkan sebuah sistem informasi mitigasi bencana banjir dengan sistem real time yang dapat memberikan informasi secara cepat dan akuran terkait dengan kebencanaan banjir, dengan memanfaatkan internet.[10]

Penelitian yang dilakukan oleh Utami \& Cahyanto,[11] merupakan salah satu sistem peringatan dini dengan memanfaatkan SMS gateway sebagai sarana memberikan informasi peringatan dini bencana banjir, sehingga pesan yang keluar dari sistem ini bisa cepat diterima oleh masyarakat

Penelitian yang dilakukan oleh Hendarsah [12] menghasilkan pemetaan yang bisa dapat mengantisipasi terhadap bencana yang disebabka oleh gunung berpai, sehingga dapat memberikan layanan informasi terhadap masyarakat.

Penelitian yang dilakukan oleh Mubekti \& Alhasanah[13], menghasilkan sebuah sistem mitigasi berbasis GIS yang dapat meberikan iformasi kepada masyarakat terkait bencana tanah longsor.

\section{METODOLOGI PENELITIAN}

Metodologi yang digunakan dalam penelitian ini didefinisikan kedalam kerangka pemikiran agar semua proses berjalan sesuai dengan yang direncanakan, secara berturut-turut mulai dari studi literatur, analisis kebutuhan sistem pengukuran menggunakan rain gauge, pembuatan website menggunakan bahasa pemrograman PHP yang merupakan bahasa pemrograman yang dijalankan melalui web, 
yang umumnya digunakan untuk internet. [14] Untuk basis data menggunakan MySQLi yang merupakan basis yang open source.[15] Untuk metode pengembangan sistem digunakanlah metode pengembangan sistem Rapid Aplication Development $(R A D)$, yang terdiri dari tiga tahapan yakni Tahap Requirements Planning (Perencanaan Persyaratan), RAD Design Workshop, Implementation (Penerapan).[16] bisa dilihat pada gambar 1 .

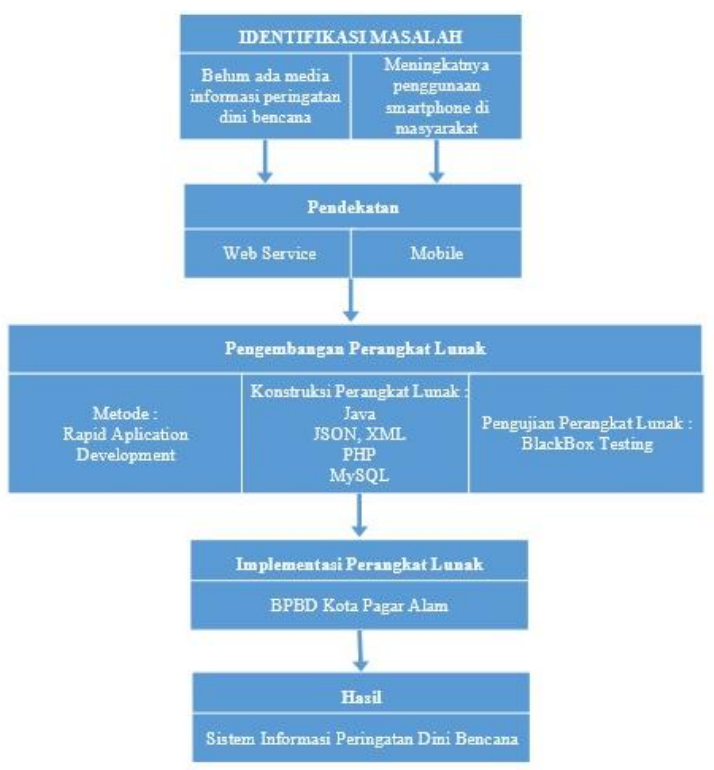

Gambar 1. Kerangka Pemikiran

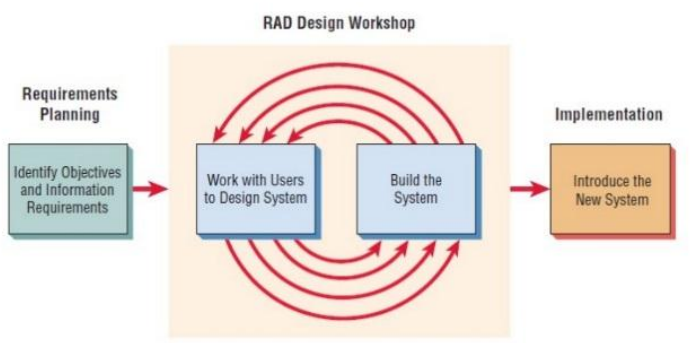

Gambar 2. Rapid Aplication Development $(R A D)[16]$

Tahapan RAD yang dimulai dari 3 fase yakni[16]:

1. Requirements Planning (Perencanaan Persyaratan), yaitu: a. Pengguna dan analis bertemu untuk mengidentifikasi tujuan dari aplikasi atau sistem.

b. Berorientasi pada pemecahan masalah.

2. RAD Design Workshop, yaitu:

a. Fase desain dan menyempurnakan.

b. Programmer dan analis membangun dan menunjukkan tampilan visual desain dan alur kerja pengguna.

c. Pengguna menanggapi prototipe kerja aktual.

d. Analis menyempurnakan modul dirancang berdasarkan tanggapan pengguna.

3. Implementation (Penerapan), yaitu:

a. Sebagai sistem yang baru dibangun, sistem baru atau parsial diuji dan diperkenalkan kepada organisasi.

Ketika membuat sistem baru, tidak perlu untuk menjalankan sistem yang lama secara parallel.

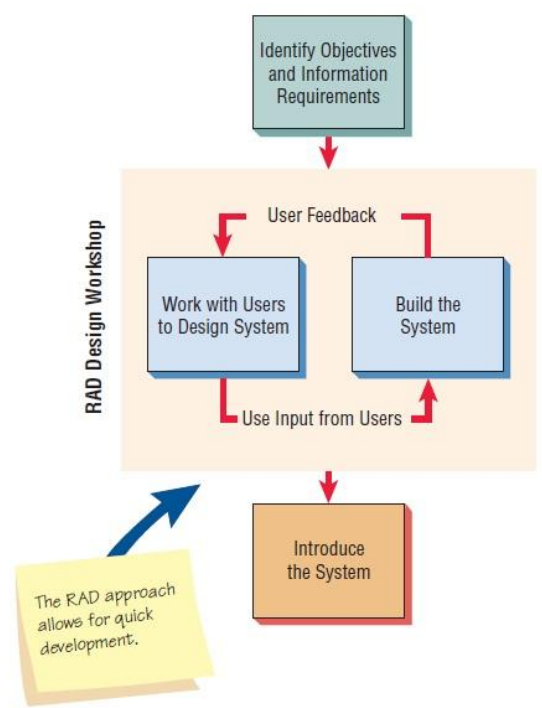

Gambar 3. Tahapan Rapid Aplication Development (RAD) 
Selanjutnya adalah merancang diagaram alur flowcart seperti yang tergambar pada gambar 3.

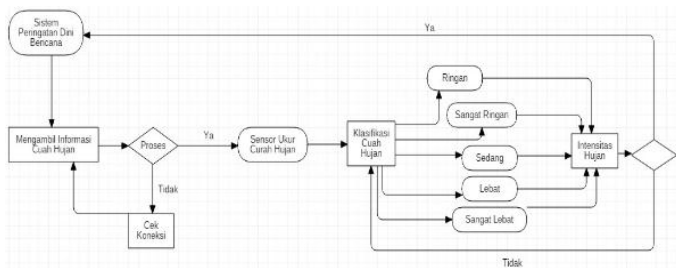

Gambar 4. Flowchart Pengambilan data rain couge

\section{HASIL DAN PEMBAHASAN}

Dalam penelitian ini dihasilkan dilakukan pengukuran terhadap curah hujan pada musim pengujan dan pengukuran suhu pada musim panas. Dalam analisa longsor yang dilakukan adalah dengan mengukur tingkat curah hujan yang turun dengan mengacu pada spesifikasi data dari BMKG. Yang terdiri dari beberapa spesifikasi, mulai dari sangat ringan, ringan, sedang, lebat dan sangat lebah. Seperti yang tampak pada tabel 1.1

Tabel 1. Pengukuran curah hujan (sumber :bmkg 2018)

\begin{tabular}{|c|c|c|}
\hline No & Klasifikasi & Rentang Nilai \\
\hline 1 & Sangat Ringan & $<5 \mathrm{~mm} /$ hari \\
\hline 2 & Ringan & $5-20 \mathrm{~mm} /$ hari \\
\hline 3 & Sedang & $21-50 \mathrm{~mm} /$ hari \\
\hline 4 & Lebat & $\begin{array}{c}51-100 \mathrm{~mm} / \\
\text { hari }\end{array}$ \\
\hline 5 & Sangat Lebat & $>100 \mathrm{~mm} /$ hari \\
\hline
\end{tabular}

Sedangkan untuk pengukuran suhu digunakan klasifikasi rendah, normal dan tinggi, hal ini mengacu pada Sebuah studi yang diterbitkan Journal of American Medical Association menemukan suhu normal rata-rata untuk orang dewasa adalah $36,7^{\circ} \mathrm{C}$, bukannya pas $37^{\circ} \mathrm{C}$. Secara umum, dunia medis menyepakati bahwa suhu tubuh normal berkisar antara $36,1^{\circ} \mathrm{C}$ sampai $37,2^{\circ} \mathrm{C}$. dan untuk tanaman bisa sampai dengan $40^{\circ} \mathrm{C}$.[17]
Tabel 2. Pengukuran suhu

\begin{tabular}{|c|c|c|}
\hline No & Klasifikasi & Rentang Nilai \\
\hline 1 & Rendah & $<25^{\circ} \mathrm{C}$ \\
\hline 2 & Normal & $25-30^{\circ} \mathrm{C}$ \\
\hline 3 & Tinggi & $>30^{\circ} \mathrm{C}$ \\
\hline
\end{tabular}

Berdasar pada data indikator curah hujan dan suhu dibuat sebuah sistem berbasis mobile dengan menggunakan bahasa pemrograman PHP dan basis data db Maria dengan struktur untuk bagian admin

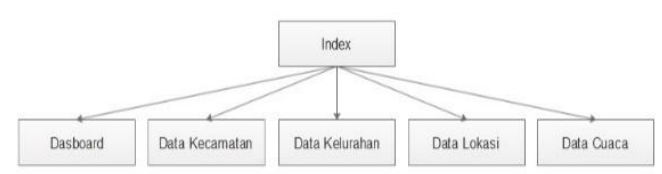

Gambar 5. Struktur menu administrator

Hasil design antar muka administrator dibuat dengan menggunakan framework bootstrap, dengan layout menu secara vertikal dan pada bagian content menunjukan data wilayah, lokasi, data curah hujan, data kebakaran, pada bagian bawah terdapat grafik monitoring kebencanaan, dan juga terdapat kalender, seperti yang nampak pada gambar berikut.

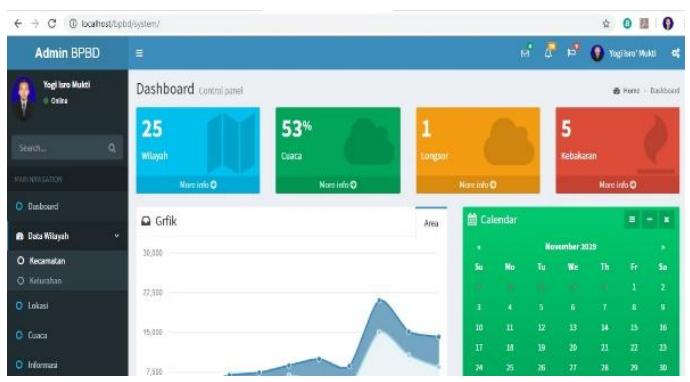

Gambar 6. Halaman Administrator

Di halaman administrator ini semua aktifitas diatur seperti proses penambahan data, perubahan data, penghapusan data dan monitoring data dilakukan. Pada menu vertikal terdiri dari menu kecamatan, kelurahan, lokasi, cuaca dan suhu 
Selanjutnya dibuat untuk halaman pengguna yang berbasiskan perangkat mobile, dengan design dengan menggunakan progresive web app, yang merupakan salah satu teknologi dalam membangun dan mengembakan aplikasi berbasis mobile secara nativ yang cepat dan fleksibel. [9] adapun design antar muka terdiri dari menu wilayah, menu kedua titik lokasi rawan bencana, menu tiga longsor dan menu keempat kebakaran hutan dan lahan, dan pada bagian bawah terdapat map wilayah Kota Pagar Alam.

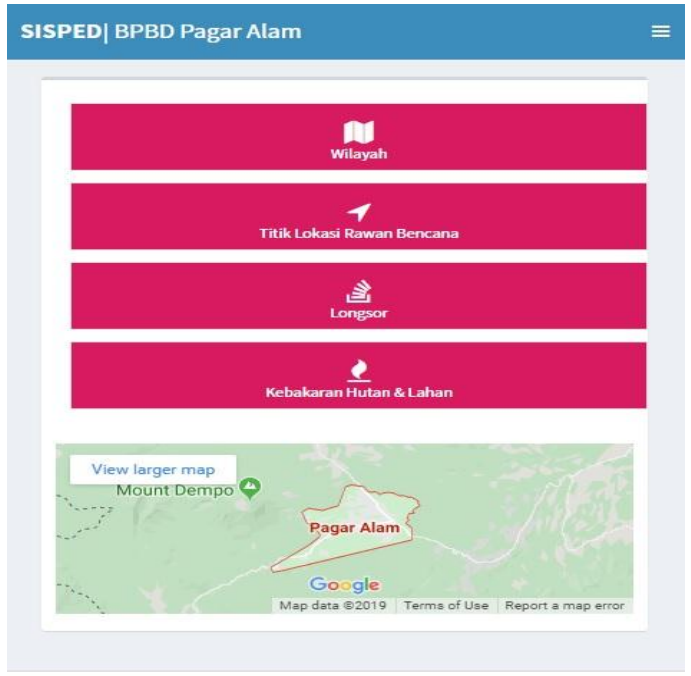

Gambar 7. Halaman utama aplikasi

Selanjutnya untuk bisa mengaktifkan notifikasi terkait kebencanaan yang menjadi sistem peringatan pengguna bisa memilih menu wilayah sesuai dengan kebutuhan atau domisili yang terdiri dari 5 kecamatan yakni Wilayah Dempo Selatan, Dempo Tengah, Dempo Utara, Pagar Alam Selatan, Pagar Alam Utara

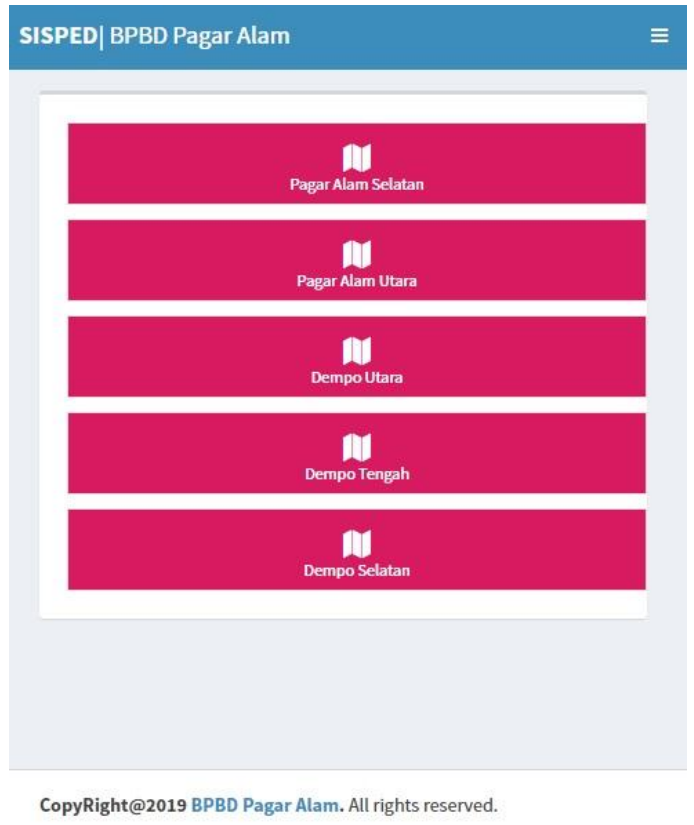

Gambar 7. Menu Wilayah kebencanaan

Setiap data dibuat ke dalam tabel guna memberikan informasi secara rinci dan terstruuktur seperti data curah hujan seperti yang nampak pada gambar berikut :

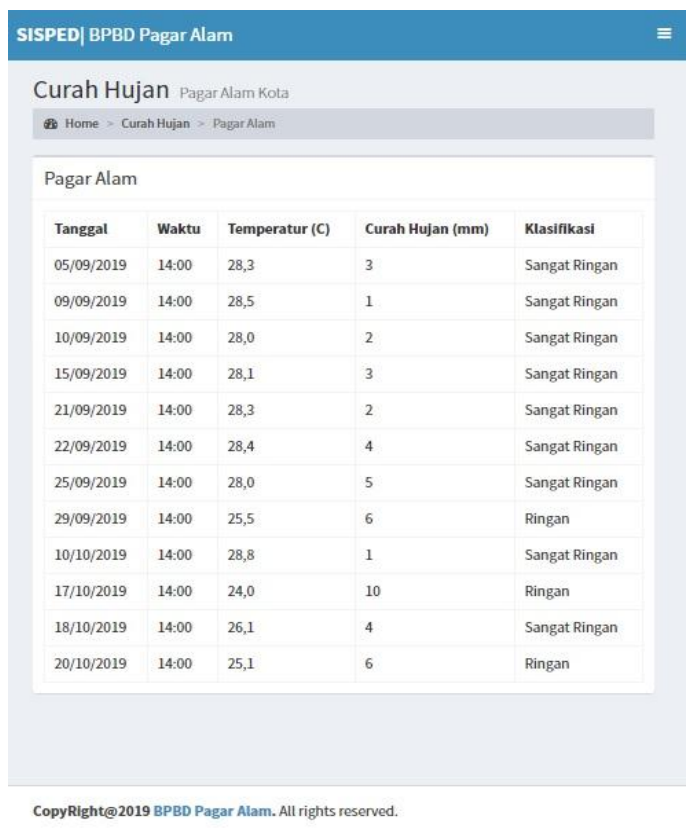

Gambar 8. Curah Hujan

Informasi curah hujan juga dibuat berdasarkan wilayah sebaran pada 5 kecamatan yang ada di Kota Pagar Alam seperti gambar berikut. 


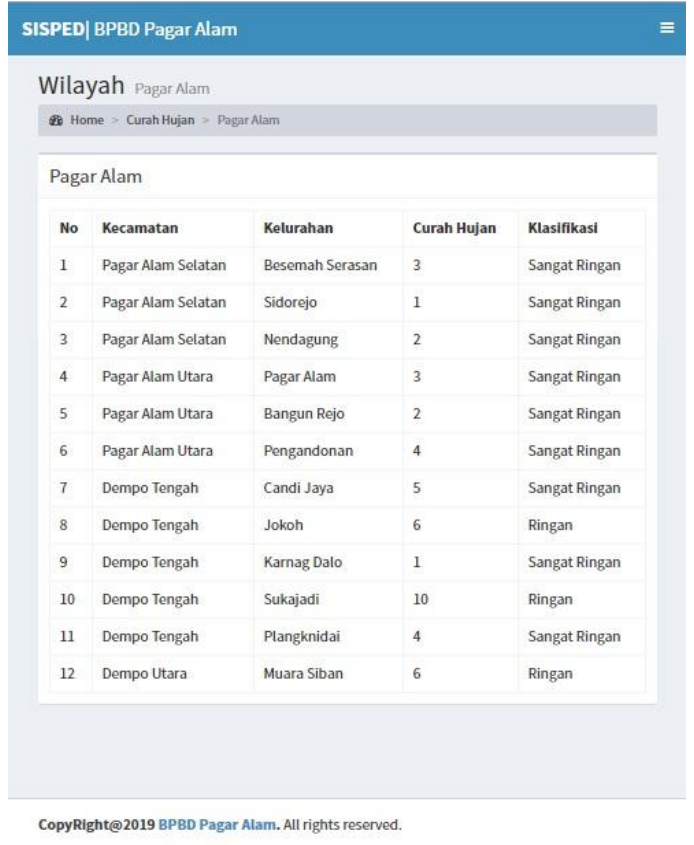

Gambar 9. Curah Hujan Berdasarkan Wilayah

Selain curah hujan tabel pada suhu udara juga dibuat dengan informasi yang menampilkan data suhu udara yang ada diwilayah Pagar Alam.

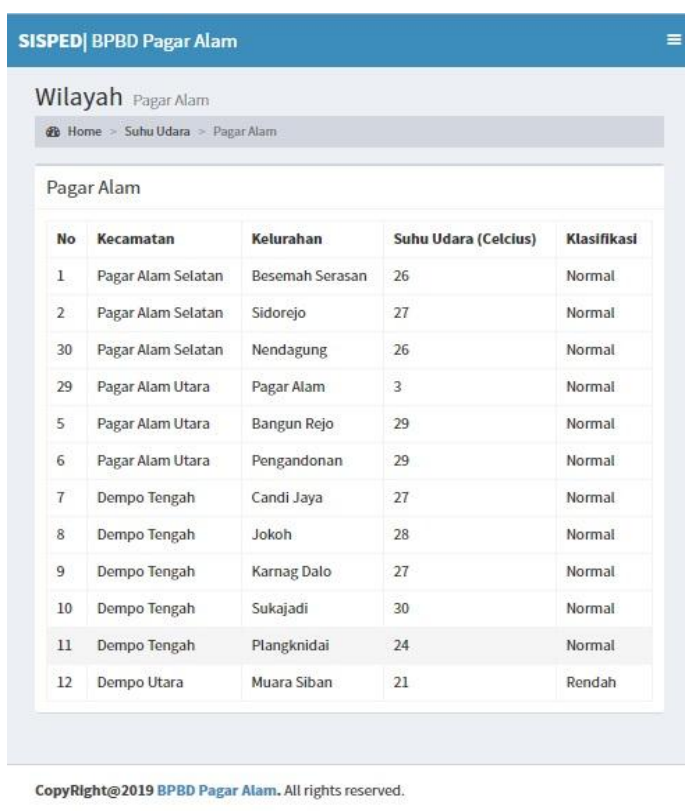

Gambar 10. Antar Muka Suhu Udara
Setelah diimplementasikan selanjutnya dilakukan pengukuran terhadap indikator kebencanaan dengan hasil sebagai berikut :

Tabel 3. Hasil Pengukuran Curah hujan perhari

\begin{tabular}{|c|c|c|c|}
\hline Tahun & Waktu & $\begin{array}{c}\text { Curah } \\
\text { Hujan } \\
\text { (mili } \\
\text { meter) }\end{array}$ & Klasifikasi \\
\hline 2019 & $0: 14$ & 3 & $\begin{array}{c}\text { Sangat } \\
\text { Ringan }\end{array}$ \\
\hline 2019 & $0: 10$ & 3 & $\begin{array}{c}\text { Sangat } \\
\text { Ringan }\end{array}$ \\
\hline 2019 & $0: 15$ & 10 & Ringan \\
\hline 2019 & $0: 13$ & 6 & Ringan \\
\hline 2019 & $0: 12$ & 4 & $\begin{array}{c}\text { Sangat } \\
\text { Ringan }\end{array}$ \\
\hline 2019 & $0: 05$ & 2 & $\begin{array}{c}\text { Sangat } \\
\text { Ringan }\end{array}$ \\
\hline
\end{tabular}

Dari pengukuran di atas klsifikasi ringan dengan informasi curah hujan rendah. Selanjutnya pengukuran pada suhu selama rentang 1 bulan dengan indikasi suhu ratarata berkisar antara $29-30{ }^{\circ} \mathrm{C}$

Tabel 4. Hasil Pengukuran suhu udara

\begin{tabular}{|c|c|c|c|}
\hline Tahun & Waktu & Suhu & Klasifikasi \\
\hline 2019 & $0: 14$ & $29^{\circ} \mathrm{C}$ & Normal \\
\hline 2019 & $0: 10$ & $30^{\circ} \mathrm{C}$ & Normal \\
\hline 2019 & $0: 15$ & $29^{\circ} \mathrm{C}$ & Normal \\
\hline 2019 & $0: 13$ & $29^{\circ} \mathrm{C}$ & Normal \\
\hline 2019 & $0: 12$ & $28^{\circ} \mathrm{C}$ & Normal \\
\hline 2019 & $0: 05$ & $30^{\circ} \mathrm{C}$ & Normal \\
\hline
\end{tabular}

Pengukuran data tersebut masih dikatakan normal dengan rentang hujan beberapa kali dalam 1 bulan selama musim panas, namun demikian jika mengalami peningkatan suhu dalam 1 bulan sistem akan memberikan notifikasi terkait bahasa kebakaran. 


\section{KESIMPULAN}

Setelah dilakukan penelitian dengan pembuatan sistem informasi peringatan dini bencana berbasis mobile dan dilakukan pengukuran dapat disimpulan sebagai berikut :

1. Sistem yang dibangun berjalan sesuai dengan yang diharapkan, yakni memberikan notifikasi jika terjadi hujan lebat, yakni dengan memperingatkan di wilayah yang teridikasi terjadi longsor.

2. Sistem yang dibangun menggunakan metode $R A D$, dengan pemrograman PHP dengan basis data dbmaria.

3. Sistem yang dibangun bersifat mobile dengan menggunakan teknologi progressive web app dan berjalan $\mathrm{di}$ berbagai perangkat mobile

\section{SARAN}

Tentunya dalam penelitian ini masih banyak yang perlu disempurnakan seperti penempatan alat ukur curah hujan dan suhu bisa diperluas lagi sehingga seluruh titik bisa termonitor dengan baik. Selanjutnaya aplikasi yang dibangun bisa benar-benar dimanfaatkan oleh semua pihak khususnya masyarakat kota Pagar Alam, sehingga bencana bisa segera diantisipasi dengan cepat. Peneliti juga mengucapkan terima kasi kepada Kemenristekdikti yang telah mendanai penelitian ini, dan juga STT Pagar Alam yang memberikan masukan dan saran terkait penelitian ini.

\section{DAFTAR PUSTAKA}

[1] Cnnindonesia, "60 Hektare Lahan di Sumsel Terbakar Sepanjang Juli," 2019. [Online]. Available: https://www.cnnindonesia.com/nasi onal/20190729194929-20-

416557/60-hektare-lahan-di-sumselterbakar-sepanjang-juli.

[2] R. A. Siregar, "Jalan Lahat-Pagar Alam Sumsel Putus Total Akibat
Longsor," detikcom, 2019. [Online]. Available:

https://news.detik.com/berita/44112

02/jalan-lahat-pagar-alam-sumselputus-total-akibat-longsor.

[3] Kominfo, "Pengguna Internet," 2018. [Online]. Available: www.kominfo.go.id.

[4] B. Hartono, Sistem Informasi Manajemen Berbasis Komputer, 1st ed. Jakarta: Rineka Cipta, 2013.

[5] J. Ward and J. Peppard, Strategic Planning for Information Systems. England, 2002.

[6] H. Saragih and Harisno, Renncana Strategis Teknologi Informasi (IT) dan Sistem Informasi (IS) Pada Proses Bisnis Perusahaan, 1st ed. Yogyakarga: Graha Ilmu, 2014.

[7] BNPB, "Definisi dan Jenis Bencana," Badan Nasional Penanggulangan Bencana (BNPB), 2019. [Online]. Available: https://bnpb.go.id//definisi-bencana.

[8] Wikipedia, "Peranti bergerak," wikipedia.org, 2019. [Online]. Available:

https://id.wikipedia.org/wiki/Peranti _bergerak.

[9] H. Santoso, Membangun Aplikasi Mobile dengan Progressive Web App. cv.lokomedia, 2019.

[10] D. Satria, S. Yana, R. Munadi, and S. Syahreza, "Sistem Peringatan Dini Banjir Secara Real-Time Berbasis Web Menggunakan Arduino dan Ethernet," vol. 1, no. 1, pp. 1-6, 2017.

[11] E. Utamai and A. D. Cahyanto, "Sistem Peringatan Dini Pada Bencana Banjir Berbasis Sms Gateway Di Gnu / Linux Merupakan Alternatif Yang Sederhana Dan Menarik Dalam Meningkatan Pelayanan Badan Meteorologi Dan Geofisika Dengan Alokasi Dana 
Yang Rendah," in SNATI, 2008, vol. 2008, no. Snati, pp. 9-14.

[12] H. Hendarsah, "Pasca erupsi Gunungapi Merapi tanggal 26 Oktober 2010, bahaya lahar merupakan ancaman bencana di wilayah Kabupaten Magelang. Kecamatan Salam merupakan daerah rawan bahaya lahar dengan keberadaan empat sungai yang berhulu di Gunungapi Merapi, yaitu Kali Kr," Sosiokonsepsia, vol. 17, no. 03, pp. 318-335, 2010.

[13] Mubekti and F. Alhasanah, "Menggunakan Teknik Pemodelan Sistem Informasi Geografis," J.Tek.Ling, vol. 9, no. 2, pp. 121129, 2008.

[14] R. Kurniawan, PHP dan MySQL untuk Orang Awam Edisi Ke-2, 2nd ed. Palembang: Maxikom, 2010.

[15] P. Andre, MySQL Uncover Panduan Belajar MySQL dan MariaDB untuk Pemula. Padang Panjang: Dunia Ilkom, 2017.

[16] K. E. Kendall and J. E. Kendall, Systems Analysis And Design Edition 8. 2010.

[17] A. Quamila, "Berapa Seharusnya Suhu Tubuh yang Normal? Apa yang Bikin Suhu Tubuh Naik-Turun?," 2017. [Online]. Available: https://hellosehat.com/hidupsehat/tips-sehat/berapa-suhu-tubuhnormal/. 